\title{
An adherent tissue-inspired hydrogel delivery vehicle utilised in primary human glioma models
}

\author{
Matthew J. Rowland ${ }^{\mathrm{a}, 1}$, Christopher C. Parkins ${ }^{\mathrm{a}, 1}$, Joseph H. McAbee ${ }^{\mathrm{b}}$, Anna K. Kolb ${ }^{\mathrm{b}}$, Robert Hein ${ }^{\mathrm{a}}$, \\ Xian Jun Loh ${ }^{\mathrm{c}}$, Colin Watts ${ }^{\mathrm{b}, \mathrm{d}}$, Oren A. Scherman ${ }^{\mathrm{a}, *}$ \\ ${ }^{a}$ Melville Laboratory for Polymer Synthesis, Department of Chemistry, University of Cambridge, Cambridge, CB2 1EW, United Kingdom. \\ ${ }^{b}$ Department of Clinical Neurosciences, Cambridge Centre for Brain Repair, University of Cambridge, Cambridge, CB2 0PY, UK \\ ${ }^{c}$ Institute of Materials Research and Engineering, $A{ }^{*} S T A R, 2$ Fusionopolis Way, Innovis, Singapore \\ ${ }^{d}$ Division of Neurosurgery, Department of Clinical Neurosciences, University of Cambridge, Addenbrooke's Hospital, Cambridge CB2 0QQ, \\ $U K$.
}

\begin{abstract}
A physical hydrogel cross-linked via the host-guest interactions of cucurbit[8]uril and utilised as an implantable drugdelivery vehicle for the brain is described herein. Constructed from hyaluronic acid, this hydrogel is biocompatible and has a high water content of $98 \%$. The mechanical properties have been characterised by rheology and compared with the modulus of human brain tissue demonstrating the production of a soft material that can be moulded into the cavity it is implanted into following surgical resection. Furthermore, effective delivery of therapeutic compounds and antibodies to primary human glioblastoma cell lines is showcased by a variety of in vitro and ex vivo viability and immunocytochemistry based assays.
\end{abstract}

Keywords: glioma, hydrogel, blood-brain barrier, cucurbit[8]uril, drug-delivery, hyaluronic acid

\section{Introduction}

Glioblastoma (GB) is the most common primary malignant brain cancer in adults and one of the most aggressive cancers. The median survival in the general patient population is just 4.6 months. 1] Even in optimally treated patients the median survival is 14 months with a $26 \%$ two year survival rate. 2, 3, 4, 5, GB infiltrates the brain tissue diffusely making complete surgical excision impossible. [6] The majority of patients (90\%) will suffer recurrence within $2 \mathrm{~cm}$ of the resection cavity due to the presence of residual disease. 7 .

Current standard of care involves surgical resection of the tumour, concomitant radiotherapy and alkylating chemotherapy (CRT), followed by adjuvant chemotherapy. 2. TMZ is the major chemotherapeutic agent used to treat GB as it is one of the few molecules that readily cross the blood-brain barrier (BBB). [8] Following uptake into the brain, TMZ is hydrolyzed into its active form MTIC enabling methylation of the O-6 position on guanine residues, resulting in cytotoxic DNA damage. 9] However, TMZ also degrades to MTIC in the blood stream which does not cross the BBB and can cause systemic toxicity, including bone marrow suppression. [10 Such toxicity sometimes requires dose reduction or termination of concomitant or adjuvant chemotherapy. Therefore, despite the use of TMZ,

\footnotetext{
* Corresponding author

Email address: oas23@cam.ac.uk (Oren A. Scherman)

${ }^{1}$ These authors contributed equally to this work
}

surgical resection and radiotherapy as standard of care, patient survival rates remain poor.

At the end of surgery, a localised and sustained delivery of patient-tailored chemotherapy to the resection cavity walls could significantly enhance patient survival opportunities by circumventing the BBB to eradicate the local, residual disease. A recent clinical trial (NCT01310868) evaluated the use of local DNA cross-linking chemotherapy (carmustine) in patients undergoing advanced surgical resection. 11 The trial delineates the benefit of antineoplastic effects from the increasingly aggressive neurooncological care patients receive, determining that the carmustine wafer added no additional patient benefit following fluorescence-guided surgery. 12 The carmustine implant takes the form of drug-loaded wafers produced from 1,3-bis- ( $p$-carboxyphenoxy)propane (CPP) and sebacic acid (SA) monomers (20:80 molar ratio) connected with anhydride bonds. The rigid wafers $\left(\right.$ Gliadel $\left.^{\circledR}\right)$ ) are administered at the end of surgery to the tumour bed. 13, 14, Such implants have the potential to cause a mechanical mismatch between the implant and surrounding tissue that could result in encapsulation of implants by fibrous tissue and a foreign body reaction. 15, 16 Once in contact with physiological fluid, carmustine is released through erosive dissolution of the matrix in a $2-3$ week period. [17, 18, 19, 20] The permanent shape and stiffness of the implant $(14 \mathrm{~mm}$ diameter, $1 \mathrm{~mm}$ depth) compromise tissue-wafer contact, which limits tumour penetration by the carmustine. 3, 21, 22, 19] Due to the strong lipophilicity of carmustine, facile 

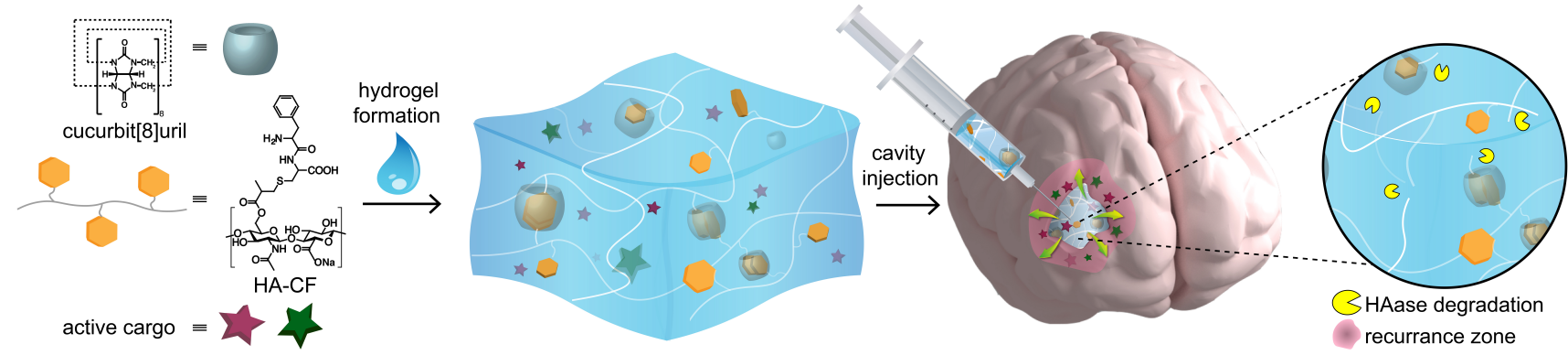

Figure 1: The hydrogel (blue) may be implanted in a tumour resection cavity via a syringe/needle. The hydrogel acts as a drug reservoir, delivering active chemotherapies through the cavity wall into the recurrence zone. The hydrogel consists of a hyaluronic acid functionalised with phenylalanine terminated peptides that bind in a 2:1 fashion with the CB[8] host providing shear-responsive crosslinks that allow for injection.

diffusion through cell membranes and into tissue is easily achievable. However, this also results in a rapid loss of carmustine from the brain into systemic circulation, forming sharp concentration gradients that span just micrometer distances from the implant site. 19 Since disease recurrence occurs within $2 \mathrm{~cm}$ of the resection cavity, the depth of carmustine penetration is insufficient and therefore median survival rates remain limited. 221, 23. The use of this local treatment remains under scrutiny because therapeutic efficacy remains unproven; the wafers are associated with an increased risk of wound infection, chemical meningitis and cerebral edema and its use can preclude patients participating in clinical trials. [21, 12] A major reason for the lack of benefit is the relative stiffness of the polyanhydride matrix leading to poor apposition with brain tissue and a propensity to move with cavitary expansion.

To address the current local delivery limitations, we set out to establish design criteria for an alternative drugdelivery platform. These criteria are listed below:

1. The delivery vehicle should be mechanically softer than surrounding brain tissue. This would prevent serious adverse side effects resulting from contact with a hard implant. A stiff implant would hamper contact interactions and therapeutic efficacy of the delivery device.

2. The material must be malleable, mouldable and injectable. The substance should be spreadable around the resection cavity but stiff and adherent enough to maintain its shape and position once applied to the treatment area. The material should also be rapidly self healing to enable immediate retention of the material and its cargo upon injection via a syringe into the cavity.

3. Cargo loading and delivery properties should be readily tailorable. Surgical staff should be able to easily formulate the delivery vehicle with appropriate cargo. This is particularly relevant for heterogeneous disease such as GB owing to the diverse cell population; a range of therapeutic resistances can be found within a single tumour mass. 6]

4. The delivery vehicle must be biocompatible and biodegradable.
Hydrogels are a class of materials that can satisfy all of these criteria. 24 Hyaluronic acid (HA), a component of the brain's extracellular matrix, can be readily functionalised with peptide residues (cysteine-phenylalanine, CF) as we have previously reported. 25] The phenylalanine side chain can form 2:1 homoternary host-guest complexes with cucurbit[8] uril ( $\mathrm{CB}[8])$ resulting in a physically crosslinked HA-CF hydrogel as illustrated in Figure 1. This polysaccharide functionalization methodology was further chosen as a degradation pathway for the hydrogel to be removed from the brain is required. This should occur at a slower rate than the required time period for drug-delivery.

\section{Materials and Methods}

All starting materials were purchased from Sigma Aldrich and used as received unless stated otherwise. Rheology was performed using a TA instruments DHR 2 rheometer. Dynamic oscillatory strain amplitude sweep measurements were conducted at a frequency of $10 \mathrm{rad} \mathrm{s}^{-1}$. Dynamic oscillatory frequency sweep measurements were conducted at a $1 \%$ oscillation strain. All measurements were performed using a $40 \mathrm{~mm}$ parallel plate geometry with a gap of $0.500 \mathrm{~mm}$ and analysed using TA Instruments TRIOS software. Live cell imaging was performed with a Leica TSP8 Confocal Laser Scanning Microscope fitted with a full live cell chamber with temperature, $\mathrm{CO}_{2}$ and humidity control, a SuperZ Galvo Stage and Auto-Focus LAS AF. MTT viability results were obtained from absorbance spectra measured with a Bio-Tek Instruments ELISA $\mu$ Quant Multiscan and analysed with Gen software. Fluorescent imaging of cell monolayers and tissue slices was performed with a Leitz DMRB Fluorescence microscope with Leica AS F software. Tissue samples were sliced to $15 \mu \mathrm{m}$ with a Leica Cryotome CM3050 S. UV/vis spectroscopy was performed by using a Varian Cary 4000 UV-vis spectrophotometer. Unless otherwise stated, primary antibodies were purchased from Abcam and these were rabbit IL6, rabbit TNF receptor 1 , rabbit IL1 beta, mouse Nestin, mouse SOX2. Secondary antibodies were purchased from Life 
Technologies and these were anti-mouse Alexa fluor 488 IgG and anti- rabbit Alexa fluor 647 IgG. Hyaluronic acid from Streptococcus zooepidemicus (1.5 MDa), the highest molecular weight commercially available was purchased. ${ }^{1} \mathrm{H}-\mathrm{NMR}(500 \mathrm{MHz})$ and ${ }^{13} \mathrm{C}-\mathrm{NMR}(125 \mathrm{MHz})$ spectra were recorded in $\mathrm{D}_{2} \mathrm{O}$, using a Bruker $500 \mathrm{MHz} \mathrm{DCH}$ Cryoprobe Spectrometer. Dialysis of the polymers was carried out by placing the reaction solutions into a dialysis tube (Spectrum Labs, Spectra/Por, standard grade regenerated cellulose dialysis membrane 6, MWCO 15,000 Daltons) which was subsequently submerged in specified aqueous solutions. The external solutions were stirred at room temperature and replaced periodically over a $72 \mathrm{~h}$ time period (ca. 4-5 times daily). The dialysed polymer solution was then transferred into a round bottom flask, frozen in a dry ice/acetone bath and lyophilized on a VirTis BenchTop Freeze Drier to yield fluffy solid materials.

\subsection{FC-CF peptide[25]}

As previously published, Boc-L-phenylalanine $N$-hydroxysuccinimide ester (Boc-Phe-OSu, $5.00 \mathrm{~g}, 13.8 \mathrm{mmol}$ ) was dissolved in DMF $(50 \mathrm{~mL})$ and triethylamine $(5.75 \mathrm{~mL}$, $41.4 \mathrm{mmol}, 3$ eq.) added. L-cystine dihydrochloride $(1.72 \mathrm{~g}$, $5.50 \mathrm{mmol}, 0.4 \mathrm{eq}$ ), was added to the solution and stirred overnight. The solution was diluted with ethyl acetate and water and then acidified with $1.0 \mathrm{M} \mathrm{HCl}$. The aqueous layer was extracted and the organic layer was washed a further four times with acidified water. The organic layer was then collected and dried with magnesium sulfate, filtered and concentrated to dryness in vacuo to yield a yellow solid. The crude residue was dissolved in a minimal amount of chloroform and recrystallised overnight. The white crystals were collected by vacuum filtration, immediately suspended in dichloromethane $(50 \mathrm{~mL})$, and $4 \mathrm{~N}$ hydrogen chloride in dioxane $(50 \mathrm{~mL})$ was added. The reaction mixture clarified on addition of the hydrogen chloride solution and the product precipitated within $2 \mathrm{~h}$. The reaction mixture was concentrated to dryness in vacuo and the white solid suspended in diethyl ether. The suspension was stirred until the precipitate appeared finely dispersed and then collected by vacuum filtration. Copious amounts of diethyl ether were washed over the solid, which was then dried under high vacuum and stored at $4^{\circ} \mathrm{C} .3,3$ 'disulfanediylbis(2-(2-amino-3-phenylpropanamido)propanoic acid) dihydrochloride Yield: $2.510 \mathrm{~g}, 75 \%$;

${ }^{1} \mathrm{H}-\mathrm{NMR}\left(\mathrm{D}_{2} \mathrm{O}, 500 \mathrm{MHz}\right) \delta(\mathrm{ppm})=7.40-7.22(6 \mathrm{H}$, $\mathrm{m}, \operatorname{Ar}-H), 7.22-7.15(4 \mathrm{H}, \mathrm{m}, \operatorname{Ar}-H), 4.65-4.55(2 \mathrm{H}, \mathrm{dd}$, $J=8.4 \mathrm{~Hz}, 5.1 \mathrm{~Hz}, \mathrm{C}-H), 4.27-4.18(2 \mathrm{H}, \mathrm{dd}, J=7.0 \mathrm{~Hz}$, $7.0 \mathrm{~Hz}, \mathrm{C}-H), 3.25-3.07$ (6H, m, HC- $H)$ 2.95-2.85 (2H, dd, $J=14.4 \mathrm{~Hz}, 8.4 \mathrm{~Hz}, \mathrm{HC}-H)$.

${ }^{13} \mathrm{C}-\mathrm{NMR}$ Spectroscopy $\left(\mathrm{D}_{2} \mathrm{O}, 125 \mathrm{MHz}\right) \delta(\mathrm{ppm})=$ $173.12(\mathrm{CO}), 168.95(\mathrm{COOH}), 133.50(\mathrm{Ar} C), 129.43(\mathrm{Ar} C \mathrm{H})$, $129.15(\mathrm{Ar} C \mathrm{H}), 128.03(\mathrm{Ar} C \mathrm{H}), 54.26(C \mathrm{H}), 52.18(\mathrm{CH})$, $38.40\left(\mathrm{CH}_{2}\right), 36.75\left(C \mathrm{H}_{2}\right)$, HRMS: calculated mass for $\left[\mathrm{C}_{24} \mathrm{H}_{31} \mathrm{~N}_{4} \mathrm{O}_{6} \mathrm{~S}_{2}\right]^{+}$: 535.1685, observed mass: 535.1697

\subsection{Functionalisation of hyaluronic acid with methacrylic anhydride}

Methacrylate addition procedure utilised previously in modifying HA. 25. Hyaluronic acid (1 g) was dissolved in $50 \mathrm{~mL}$ water. Dimethylformamide (DMF, $30 \mathrm{~mL}$ ) was added and the solution stirred until homogeneous. The polymer solution was then cooled to $5{ }^{\circ} \mathrm{C}$ in an ice/water bath and methacrylic anhydride $(740 \mu \mathrm{L}, 5.00 \mathrm{mmol})$ added drop-wise over a period of fifteen minutes. The reaction mixture was removed from the ice bath and the $\mathrm{pH}$ maintained between $8-10$ for $4 \mathrm{~h}$ by addition of $0.5 \mathrm{M} \mathrm{NaOH}(\mathrm{aq})$ before being left to stir overnight. The reaction mixture was then transferred directly to dialysis tubing (MWCO $15 \mathrm{kDa}$ ) and dialysed against water for 5 days. The polysaccharide was then obtained by lyophilisation in yields upwards of $88 \%$ and functionalisation with methacrylate observed by ${ }^{1} \mathrm{H}$ NMR. Yield: $880 \mathrm{mg}, 88 \%$; Degree of MA functionalisation: $15 \%$;

${ }^{1} \mathrm{H}$ NMR: $\left(\mathrm{D}_{2} \mathrm{O}, 500 \mathrm{MHz}\right) \delta(\mathrm{ppm})=6.21-5.97(1 \mathrm{H}$, s, vinyl- $H), 5.75-5.58(1 \mathrm{H}, \mathrm{s}$, vinyl- $H), 4.56-2.57(36 \mathrm{H}, \mathrm{br}$, polysaccharide backbone), 2.14-1.69 (9H, s, -NHCOC $H_{3}$ and $3 \mathrm{H}$, s, allyl- $H$ ).

\subsection{Michael addition of FC-CF to $H A-M A s$}

Hyaluronic acid-methacrylate (HA-MA, $400 \mathrm{mg}$ ) was dissolved in PBS solution (100 mM, $100 \mathrm{~mL})$ and degassed with nitrogen for $1 \mathrm{~h}$ in darkness. Separately, FCCF (929 mg, $1.54 \mathrm{mmol}$, 10 molar equivalents to MA residues) was dissolved in water $(5 \mathrm{~mL})$ and triethylamine (1.28 mL, $9.24 \mathrm{mmol}, 6.00 \mathrm{eq}$ ) added. The peptide precipitated on addition of the base and then re-dissolved. The solution was degassed with nitrogen for $15 \mathrm{~min}$ before the addition of DL-dithiothreitol (DTT, $235 \mathrm{mg}, 1.53 \mathrm{mmol}$, $1 \mathrm{eq})$. The reaction mixture was stirred for $4 \mathrm{~h}$ and then injected into the degassed HA-MA solution and stirred continuously overnight. The solution was then transferred to dialysis tubing and dialysed against brine for 3 days and then water for 2 days. The functional polysaccharide was then isolated by lyophilisation, degree of functionalisation estimated by ${ }^{1} \mathrm{H}$ NMR and the consumption of methacrylate observed to be $100 \%$. Yield: $332 \mathrm{mg}, 83 \%$; Degree of CF functionalisation: $10 \%$;

${ }^{1} \mathrm{H}$ NMR: $\left(\mathrm{D}_{2} \mathrm{O}, 500 \mathrm{MHz}\right) \delta(\mathrm{ppm})=7.47-7.17(5 \mathrm{H}$, $\mathrm{m}$, aryl- $H$ ), 4.57-2.53 (65H, br, polysaccharide backbone), 2.16-1.73 (15H, s, -NHCOC $\left.H_{3}\right), 1.24-1.04\left(3 \mathrm{H}, \mathrm{s}, \mathrm{CH}_{3}\right)$.

\subsection{Hydrogel formation and drug loading}

Before constitution of the hydrogels, all components and equipment (stirrer bars, vials, etc.) were irradiated with UV-C (240nm) light for $1 \mathrm{~h}$. HA-CF was dissolved in cell culture media (defined below) at a concentration of $20 \mathrm{mg} \mathrm{mL}{ }^{-1}$ (2 wt.\%). CB[8] was added $\left(5 \mathrm{mg} \mathrm{mL}^{-1}\right.$, $0.5 \mathrm{wt} . \%$ ) and the mixture stirred for $2 \mathrm{~h}$ until it expressed viscoelastic properties. At this point either doxorubicin (Sigma Aldrich) or cisplatin (Cambridge Bioscience Ltd) was added to the hydrogel at a concentration of $1 \mathrm{mg} \mathrm{mL}^{-1}$ 
(0.1 wt.\%) and stirred until homogeneous. FITC-AntiCD44 (human, Miltenyi Biotec Ltd) hydrogel was prepared slightly differently by dissolving HA-CF polymer in $1 \mathrm{~mL}$ of the purchased antibody solution instead of SF media.

\subsection{Culture media}

Cells were cultured under serum-free (SF) conditions. The SF media consisted of phenol-free Neurobasal-A (NBA) (Invitrogen, UK) with $20 \mathrm{mM}$ L-glutamine, $1 \% \mathrm{v} / \mathrm{v}$ penicillin, streptomycin and fungicid (PSF) solution, $20 \mathrm{ng} \mathrm{mL} \mathrm{m}^{-1}$ human epidermal growth factor (hEGF, Sigma, UK), $20 \mathrm{ng} \mathrm{mL}$ human fibroblast growth factor (hFGF, RD systems, UK), $2 \% \mathrm{v} / \mathrm{v}$ B27 (Invitrogen, UK) and 1\% $\mathrm{N}_{2} \mathrm{v} / \mathrm{v}$ (Invitrogen, $\mathrm{UK})$. All cell cultures were grown in appropriate incubators at $37^{\circ} \mathrm{C}$ in $5 \% \mathrm{CO}_{2}$.

\subsection{Cell culture}

Ethical approval was obtained for use of human material LREC ref 04/Q0108/60. Each GB specimen was anonymized, weighed, cut into small pieces and dissociated enzymatically using a mixture of Accutase (Invitrogen, UK) in $\mathrm{HBSS} \mathrm{Ca}{ }^{2+} / \mathrm{Mg}^{2+}$ free. The suspension was filtered through a $40 \mu \mathrm{m}$ strainer (Falcon, UK) to isolate single cells. For removal of red blood cell, the single cell suspension was washed with filtered red cell lysis buffer consisting of $\mathrm{NH}_{4} \mathrm{Cl}(8.3 \mathrm{~g}), \mathrm{KHCO}_{3}(1.0 \mathrm{~g})$ and $5 \%$ of EDTA $(1.8 \mathrm{~mL})$ in double distilled $(\mathrm{dd})$ water $(1 \mathrm{~L})$. Cells were rewashed in HBSS $\mathrm{Ca}^{2+} / \mathrm{Mg}^{2+}$ free before quantification of live cells by trypan blue exclusion. Cells were seeded at standard density of 15,000 cells per $\mathrm{cm}^{2}$ in defined $\mathrm{SF}$ medium in $37^{\circ} \mathrm{C}, 5 \% \mathrm{CO}_{2}$ incubator. All primary cultures monitored daily for primary neurosphere formation. Primary neurosphere cultures were rewashed and fed weekly for 2-6 weeks depending on the sample. After a variable priming period in which primary spheres size increased, spheres were harvested, washed once in HBSS $\mathrm{Ca}^{2+} / \mathrm{Mg}^{2+}$ free before being seeded without dissociation on ECM-coated flasks (Nunc, Thermo Scientific) to grow as primary monolayer cultures. As the primary monolayer approached confluence cells were dissociated by incubation with Accutase at room temperature and washed with HBSS $\mathrm{Ca}^{2+} / \mathrm{Mg}^{2+}$ free. The cell viability was assessed by trypan blue exclusion and cells reseeded onto ECM-coated flasks at a density of 15,000 cells per $\mathrm{cm}^{2}$ to generate the subsequent monolayers. Cells were grown in 96 well plates, sterilised coverslips in 24 well plates or in T25 and T75 flasks. Extracellular matrix gel (ECM) from Engelbreth Holm-Swarm mouse sarcoma (Sigma) was used as adhesive substrate after being dilute 1:10 in phenol-free NBA (Gibco) before coating the flasks.

\subsection{MTT assay for drug delivery experiments}

In a typical experiment, cells were seeded at a density of 40,000 cells per well into 324 -well plates pre-coated with ECM and incubated for 2 days in $1 \mathrm{~mL}$ of defined $\mathrm{SF}$ media in $37{ }^{\circ} \mathrm{C}$ and $5 \% \mathrm{CO}_{2}$. There were 6 replicas in each repeat per cell line. Following incubation, hanging cell culture inserts (Millipore, PET, $0.4 \mu \mathrm{m}$ ) containing either $100 \mu \mathrm{l}$ of drug loaded hydrogel, hydrogel, drug or SF media (no treatment). The cells were then incubated for a further $72 \mathrm{~h}$ prior to the removal of the hanging inserts and addition of $20 \mu \mathrm{l}$ of MTT solution (Sigma Aldrich) into each. Following a further incubation period of $4 \mathrm{~h}$, the media was removed and the purple formazan crystals solubilized in $500 \mu \mathrm{l}$ of DMSO. Optical absorbance values at $570 \mathrm{~nm}$ from each well were recorded using a plate -1eader. Absorbance values measured from wells containing no cells were used as blank controls. Percentage cell viability was then assessed by adjusted absorbance values whereby the average absorbance values of the control wells was subtracted from the experimental well values and the corresponding value then analyzed as a percentage of the absorbance from the no treatment wells.

\subsection{Immunocytochemistry and fluorescent imaging}

Preceding treatment with hanging wells loaded with hydrogel formulations, cells were cultured in 24-well plates equipped with coverslips. After treatment of the cell lines for $72 \mathrm{~h}$, hanging wells were removed and the coverslips washed three times with PBS. The coverslips were then fixed with ice cold methanol and incubated for $10 \mathrm{~min}$ at $4^{\circ} \mathrm{C}$. The coverslips were then washed with further PBS (x3) and then carefully dried by absorbing any residual fluid with a tissue. Coverslips were then transferred to petri dishes coated with parafilm to provide a hydrophobic surface. Blocking buffer (PBS/A) was added to the surface of the coverslip, left to stand for $45 \mathrm{~min}$ and then removed. Primary antibodies were then added to the cells monolayers at a supplier recommended concentration $(75 \mu \mathrm{l}$ a coverslip) and incubated at RT for $90 \mathrm{~min}$. This solution was then removed and coverslips washed with PBS (x3) and secondary fluorescent antibodies added at supplier recommended concentrations and incubated in darkness for a further $45 \mathrm{~min}$. At this point the liquid was removed from the coverslip, washed with PBS (x3) followed by doubly distilled water $(\mathrm{x} 3)$ and then mounted onto slides with DAPI containing fluorsave. Imaging was performed by exciting DAPI, rhodamine, doxorubicin and FITC labelled markers by using the blue, red and green channels fitted to a fluorescent microscope.

\subsection{FITC labelling of HA-CF polymer}

To a solution of HA-CF (100 mg) in water $(25 \mathrm{~mL})$ was added fluorescein-isothiocyanate $(1 \mathrm{mg})$ and stirred overnight in darkness. The reaction mixture was then transferred to dialysis tubing and immersed in water. The water was changed three times daily until the dialysis solution no longer had a yellow colour and the polymer was recovered by lyophilization. 


\subsection{Hydrogel implantation and immunocytochemistry}

Pieces of human GB tissue were obtained from anonymized surgical samples. All tissue was obtained with full permission under the relevant national and local authorities, and with consent of all patients involved. $10 \mu \mathrm{l}$ of FITC labelled $\mathrm{HA}-\mathrm{CF} / \mathrm{CB}[8]$ hydrogel with encapsulated rhodamine $\mathrm{B}$ or doxorubicin (0.1 wt.\%) was injected into the centre of the tissue sample. Control samples received FITC labelled hydrogels without any cargo. Rhodamine hydrogel tissue samples were then incubated in defined cell culture media at $37^{\circ} \mathrm{C}$ for $24 \mathrm{~h}$, doxorubicin loaded samples were incubated for $1 \mathrm{~h}$ and then fixed by soaking in 4\% paraformaldehyde in PBS overnight. The samples were then cryo-protected by incubating in solutions of increasing sucrose concentrations $(10 \%, 20 \%$ and $30 \%)$ at $4{ }^{\circ} \mathrm{C}$ overnight. After incubation, tissue samples were embedded in OCT compound with incorporated DAPI, frozen at $-20{ }^{\circ} \mathrm{C}$ and then sliced into $15 \mu \mathrm{m}$ sections using a cryotome and mounted onto microscope slides. Slices were imaged using a fluorescent microscope, exciting at $360 \mathrm{~nm}$, $510 \mathrm{~nm}, 488 \mathrm{~nm}$ and $495 \mathrm{~nm}$ for DAPI, rhodamine B, doxorubicin and FITC respectively.

\section{Results}
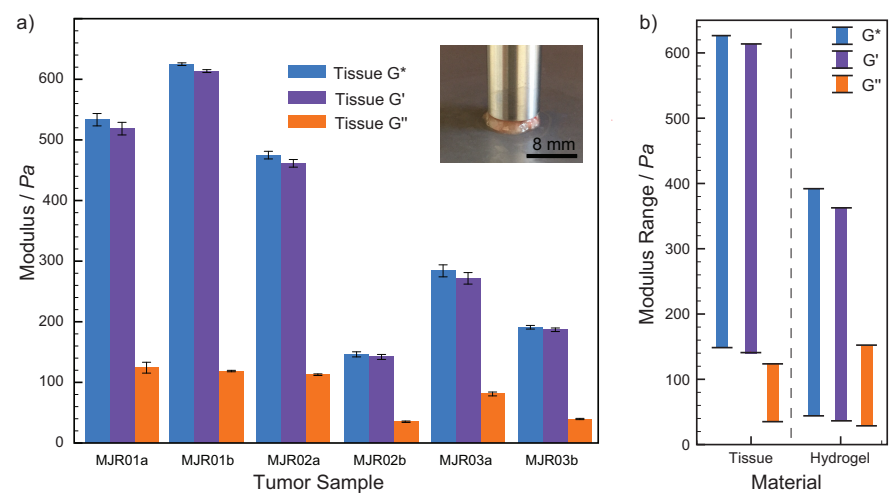

Figure 2: Rheology of brain tumour samples a) storage $\left(\mathrm{G}^{\prime}\right)$, loss $\left(\mathrm{G}^{\prime \prime}\right)$, and complex $\left(\mathrm{G}^{*}\right)$ moduli of surgically resected human brain tissue. A wide distribution of moduli were recorded between 30 and $650 \mathrm{~Pa}$. Inset is brain tissue on rheometer undergoing time-scan with an $8 \mathrm{~mm}$ geometry. b) The range of observed moduli compared to the achievable hydrogel moduli. Measurements recorded by time scan at $1 \%$ strain, $10 \mathrm{rad} \mathrm{s}^{-1}$. Error bars represent 1 standard deviation.

To allow correct selection and tailoring of hydrogel formulations, rheological characterization of freshly excised human brain tumour tissue was performed (Figure 2a). A selection of anonymized tissue samples were taken from two distinct locations in each tumour of three separate patients. Rheology of the tissue samples was measured at $20{ }^{\circ} \mathrm{C}$ to minimize tissue degradation and also limit dehydration of the samples. 26] A large degree of variation between each of the samples was recorded eluding to the heterogenous biophysical properties of the tissue, particularly in the case of $\mathrm{G}^{\prime}$ (elastic component), whereby the spread of values ranged from 140-620 Pa. Recorded $\mathrm{G}^{\prime \prime}$ (viscous component) values were much lower (40-130 $\mathrm{Pa}$ ) than $\mathrm{G}^{\prime}$ as would be expected from such a material. $\mathrm{G}^{*}$ (complex modulus) values were also collected as a way of inferring the tissue's overall resistance to deformation.

The HA-CF/CB[8] hydrogel was formulated such that the maximum $G^{\prime}$ value falls within the range of $G^{\prime}$ for the resected tissue, which was readily accomplished by altering the HA-CF and $\mathrm{CB}[8]$ concentrations (Figure 2b, see Supporting Information for full rheological characterization). A formulation consisting of 2 wt.\% HA-CF hydrogel cross-linked with 0.5 equivalents of $\mathrm{CB}[8]$ (compared to the pendant Phe groups, $10 \%$ functionalization) ensured that the supramolecular hydrogel was not as stiff as the brain tissue, thus maintaining and reinforcing good contact at the gel-tissue interface to promote continued drug diffusion into marginal tissue. Following resection, as the brain cavity reshapes, the hydrogel will be able to adapt on account of the difference in $\mathrm{G}^{\prime \prime}$ values, i.e. the brain will likely deform elastically thereby exerting a force on the hydrogel, which will dissipate by viscous flow.

Temperature dependency was also studied for the HA$\mathrm{CF} / \mathrm{CB}[8]$ hydrogels (Supporting information Figure S1b). While 1 wt.\% HA-CF/CB[8] hydrogels exhibit temperature sensitivity, 2 wt.\% hydrogels are mostly resistant to temperature change. This is likely on account of two factors, a larger amount of polymer entanglements arising from a higher concentration and the increase in concentration of phenylalanine $(\mathrm{F})$ binding units. All hydrogel formulations exhibited a frequency dependence with an increase in moduli as a function of applied oscillatory frequency, Figure S1c-d. Crossover points of $\mathrm{G}^{\prime}$ and $\mathrm{G}^{\prime \prime}$ occurred at lower frequencies with higher $\mathrm{CB}[8]$ concentrations, indicative of the $\mathrm{CB}[8]$ physical cross-links controlling the level of reordering and restructuring possible through 2:1 complex formation.

\subsection{Therapeutic Delivery}

HA-CF/CB [8] hydrogels were applied to primary GB cell lines derived from several different human patients. Patient-derived primary cell lines are in vitro models that are more representative of heterogeneous tumour cell populations and can recapitulate many of the histological features of the parent tumour. [27, 28] Two structurally different small molecule drug compounds, doxorubicin and cisplatin, were initially selected for delivery to the cell lines based on previously reported good activity against GB in vitro. 29, 30] Drug compounds were loaded into the hydrogel at a concentration of $0.1 \mathrm{wt} . \%$. This represents concentrations that are significantly higher than reported $\mathrm{IC}_{50}$ values for both drugs, and therefore even with a slow release of drug from the hydrogel, a good therapeutic response should be observed. 30 Without a drug loading, there was no significant cell death from exposure to the HA-CF/CB[8] hydrogel, which corroborates toxicity findings (Supporting Information Figure S4). Incorporation of either doxorubicin or cisplatin into the hydrogel led to a 
40-60\% drop in viability (Figure 3). Therefore, it is clear that a cytotoxic amount of chemotherapeutic compound was delivered from the hydrogel and onto the GB cell monolayer resulting in cell death. Despite high maximum deliverable concentrations, decreasing the cell viability toward $0 \%$ was not achieved and this could be for a variety of reasons. It is possible that only a small amount of drug was released from the gel.31 However, when comparing the cargo-loaded hydrogels to drug solutions of the same concentration, we see a similar final cell viability. Alternatively, as this study uses highly heterogeneous primary cell populations, it may be that largely resistant fractions are prevalent in the monolayers, and that these cells survive treatment. Finally, the drug might react with the HA-CF polymer and change the release profile (See Supporting Information for full rationale, Figure S8).

\subsection{GB live-cell imaging}

Live-cell confocal imaging was undertaken for cells receiving HA-CF/CB[8] hydrogels loaded with doxorubicin, Figure 3. Accumulation of fluorescently active doxorubicin $\left(\lambda_{e} x=480 \mathrm{~nm}, \lambda_{e} m=575 \mathrm{~nm}\right)$ within cell nuclei can be observed (Figure 3. 32 The cells appear to have reduced in population with fewer dendrons, indicating an unhealthy cell culture, compared to control treatments of unloaded $\mathrm{HA}-\mathrm{CF} / \mathrm{CB}[8]$. In both control experiments there are considerably more cells, with a number appearing to be 'rounding off' for cellular division. 33

In a second delivery experiment to investigate the ability of HA-CF / CB [8] hydrogels to deliver larger biomolecules, FITC-labelled human anti-CD44 antibody (MW=79 kDa), of which CD44 is a prevalent cell surface marker of GB, 34 was successfully delivered to the cell monolayers via the hydrogel (Figure 3).

\subsection{Immunocytochemistry}

Immunocytochemistry (ICC) was used to image the GB cell lines for relative visual quantification of proliferative or inflammatory markers post-exposure to the HA$\mathrm{CF} / \mathrm{CB}[8]$ hydrogel or cargo-loaded hydrogels (Figure 4 cisplatin-loaded hydrogels in Figure S5). High concentrations of the proliferative markers (SOX2 35, Nestin 36]) are present in the cells that received either no treatment or were just exposed to the hydrogel formulation (Figure 4A1-2, B1-2) However, when doxorubicin-loaded hydrogels were applied to these lines (Figure 4C1-2), a clear decrease in these markers was observed. Inflammatory markers IL1 $\beta$ [37, IL6 38, and TNF $\alpha$ 39] were also studied. In the control and hydrogel only samples, these markers are not visible, inferring normal stress or inflammatory levels within the cell. However, the cells exposed to doxorubicin-loaded hydrogel show clear up-regulation of IL1 $\beta$ and IL6 in comparison to the untreated lines. TNF $\alpha$ is prevalent in all cells but is severely up-regulated in those treated with the doxorubin-loaded hydrogel, providing further evidence for increased inflammation and cell stress.
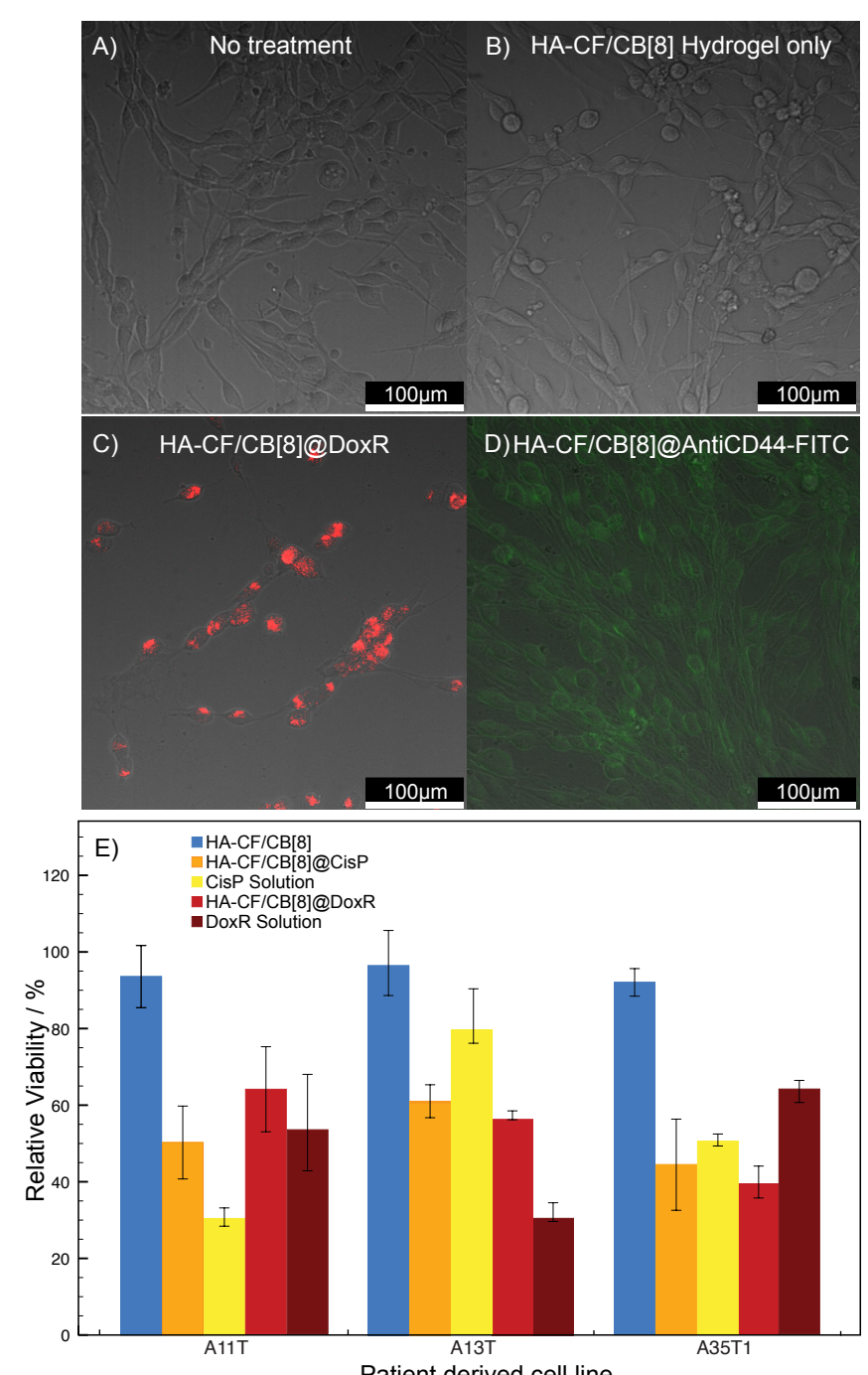

Figure 3: Live cell imaging of primary GB cells. A) cells following no treatment. B) cells following exposure to $\mathrm{HA}-\mathrm{CF} / \mathrm{CB}[8]$ hydrogel. C) cells following treatment with doxorubicin-loaded hydrogel, doxorubicin can be seen accumulating within the cells (red areas). D) FITC-antiCD44 (green) delivered from hydrogel to GB monolayer resulting in labelling of the cell surface and no detrimental changes to the cell morphology. Viability of primary GB cell lines following $72 \mathrm{~h}$ of exposure to either $2 \mathrm{wt} \% \mathrm{HA}-\mathrm{CF} / \mathrm{CB}[8]$ hydrogel alone or with incorporated doxorubicin(DoxR) or cisplatin (CisP) (0.1 wt\%). Controls were used with DoxR and CisP at the same concentration in PBS. Cells treated with hydrogel only showed good viability at the end of the treatment in comparison to controls with no treatment at all (normalized to 100\%). Doxorubicin and cisplatin treated cells saw significant decreases in the viability on account of cytotoxic chemotherapy effect. Error bars represent one standard deviation, $\mathrm{n}=3$.

Overall, the ICC results provide further evidence that the $\mathrm{HA}-\mathrm{CF} / \mathrm{CB}[8]$ hydrogel does not have a negative effect on the cells when applied in vitro and is likely to be non-toxic if used in vivo. Moreover, when doxorubicin is loaded into the hydrogel, a cellular inflammatory response can be induced by diffusion of a chemotherapy from the hydrogel formulation to the cells. 

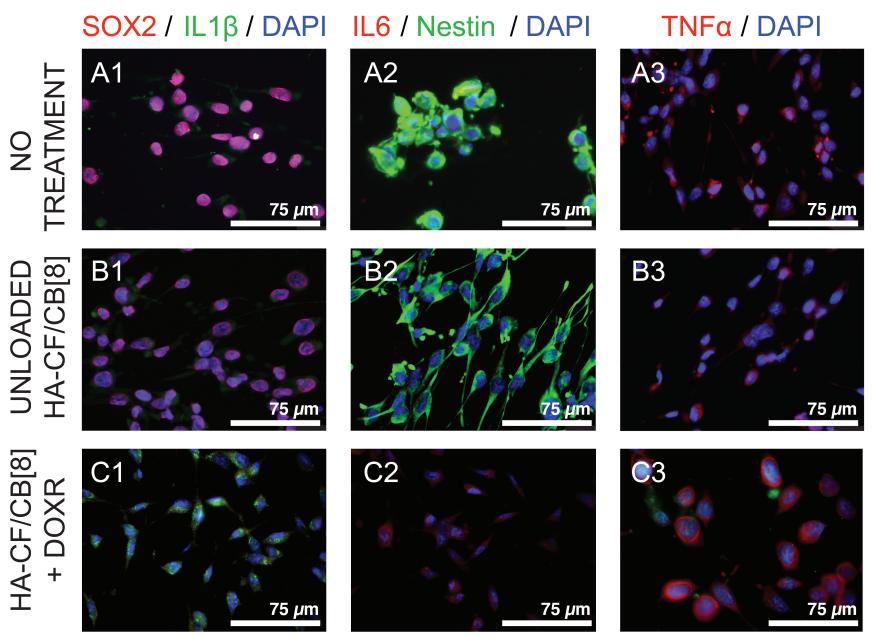

Figure 4: Representative fluorescent imaging of primary GB lines post-treatment with immunocytochemistry staining. A1-3) GB cells exposed to no treatment. B1-3) cells exposed to hydrogel treatment. C1-3) cells exposed to hydrogels containing doxorubicin. (See also supporting information Figure S5 for HA-CF/CB[8] hydrogel containing cisplatin.)

\subsection{Drug release studies}

The release of doxorubicin from 2 wt. $\% \mathrm{HACF} / \mathrm{CB}[8]$ hydrogels was quantified using $\mathrm{UV} /$ vis spectroscopy, whereby release media was periodically sampled and cumulative release of the cargo obtained (Supporting Information Figure S3). An initial linear bolus release of doxorubicin was observed within the first $10 \mathrm{~h}$, where $8 \%$ of the loaded cargo was released. Further monitoring up to $50 \mathrm{~h}$ demonstrated a slow release, achieving $11 \%$ of the total cargo. Release rate from supramolecular hydrogels can be altered in an array of methodologies. Introducing modifications to parent-polysaccharide $\mathrm{M}_{w}$, guest moiety kinetics, guest functionalisation percentage, $\mathrm{CB}[8]$ host content and the formulation conditions allow for fine tuning of the release kinetics from the hydrogel. 40, 41, 31.

A natural component of the brain that would contribute to the continued release of cargo is hyaluronidase (HAase). 42] This enzyme can cleave the HA polysaccharide within the material, reducing the moduli of the hydrogel (by shortening of the HA backbone), thereby increasing cargo release, as demonstrated in Figure 5 a.

\subsection{Ex-vivo tumour injections}

To further evaluate the diffusion of compounds from the hydrogel when injected into tissue, a simple model $e x$ vivo injection procedure was designed and utilised. In this experiment, a piece of freshly-resected brain tumour tissue was injected with FITC-labelled HACF/CB[8] hydrogel with encapsulated cargo. The samples were incubated at $37{ }^{\circ} \mathrm{C}$ before fixation in paraformaldehyde. Figure 5 shows that the hydrogel itself remains localised at the injection point and does not display diffusion through the tissue, whereas the rhodamine B or doxorubicin cargo does diffuse out of the hydrogel and penetrates into the brain tissue over 24 or $1 \mathrm{~h}$ respectively (further rhodamine b and doxorubicin images in Supporting Information Figure $\mathrm{S} 6$ and $\mathrm{S} 7$ respectively). In addition, good apposition between hydrogel and tissue at their interface is observed in Figure 5. Diffusion of rhodamine B into surrounding GB tissue can be seen up to $1000 \mu \mathrm{m}$ within $24 \mathrm{~h}$ post injection (Supporting Information Figure S6a). Doxorubicin can be clearly seen within the cell nuclei within $1 \mathrm{~h}$ post-injection up to $950 \mu \mathrm{m}$ (Figure 5d). Imaging also seems to delineate a zone in which nuclei take up only the drug, which may be considered a dead zone extending to $400 \mu \mathrm{m}$. A further zone in which drug has diffused and is uptaken by the cells can also be visualized between $400-950 \mu \mathrm{m}$.

\section{Discussion}

\subsection{Biocompatibility}

The first major hurdle in developing an implantable drug-delivery device is biocompatibility. It is well known that due to their high water content $(>90 \%)$ that hydrogels are good candidates for biocompatible materials. 40 , 31] HA-CF/CB[8] hydrogels are produced from hyaluronic acid polysaccharide backbones that are functionalized with naturally-occurring amino acids. 25] We have demonstrated that there was no toxicity in vitro associated with the hydrogels. In fact, inflammatory markers remained low and viability remained high despite the introduction of the hydrogels. Only those hydrogels carrying chemotherapeutic agents showed significant inflammatory response (Figure 4). Additionally, it was observed during live cell imaging that cells treated with the $\mathrm{HA}-\mathrm{CF} / \mathrm{CB}[8]$ control showed good proliferation, and appeared healthy (Figure 3). While the hydrogel should be able to remain in the brain for several weeks-months after surgery for a slow and sustained therapeutic release of its cargo, it is also important that there is a pathway for eventual degradation of the material, and that these degradation products are also biocompatible. Our hyaluronidase enzymatic release studies (Figure 5, and previously published long-term protein release studies, demonstrate that release can occur for extended periods of time and that enzymes present within the brain can degrade the gels. 31. It is thought that the eventual degraded products would be oligomeric saccharides (including glucuronic acid) 43, the dipeptide cysteine-phenylalanine that forms the pendant physical cross-links 25] bound within cucurbit[8]uril has been shown to cause no significant drop in cell viability in vitro in this study, and previously in vivo. 40. These results suggest that inert polymers can be utilised in an in vivo setting for treating GB.

\subsection{Efficacy}

We have demonstrated that $\mathrm{HA}-\mathrm{CF} / \mathrm{CB}[8]$ hydrogels have the potential to avoid drawbacks present within Gliadel ${ }^{\circledR}$ wafers. The hydrogel delivery platform offers a material 
a)

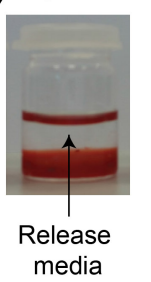

$50 \mathrm{~min}$

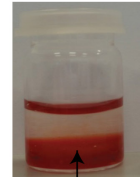

$\mathrm{HA}-\mathrm{CF} / \mathrm{CB}[8]$ @Dox
$7 \mathrm{~h}$

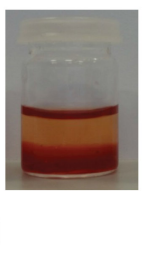

$15 d$

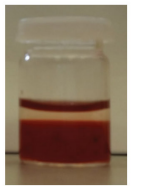

b)

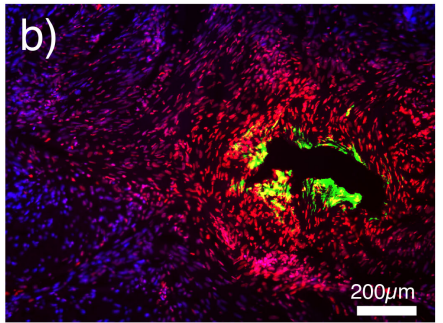

d)

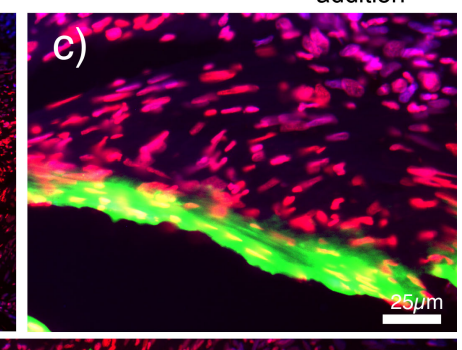

.

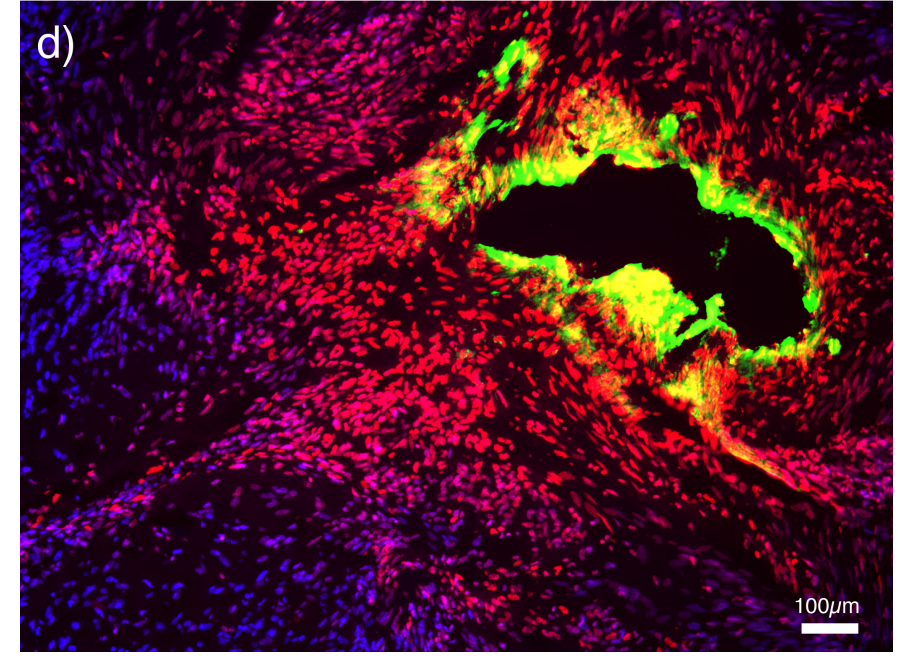

Figure 5: A) Doxorubicin loaded hydrogels were stable for a period of up to $15 \mathrm{~d}$ expressing good retention of doxorubicin cargo at $37^{\circ} \mathrm{C}$. Addition of $1 \mathrm{~mL}$ of HAase $\left(5000 \mathrm{U} \mathrm{mL}^{-1}\right)$ in PBS and incubation for $24 \mathrm{~h}$ afforded complete degradation of the hydrogel and release of the remaining doxorubicin into the now homogeneous free flowing. Fluorescent microscope imaging of hydrogel injected into human GB tissue samples. B-C) injection site of hydrogel loaded with doxorubicin. Penetration into the cellular nucleus is observed in red (purple if DAPI also present) D) radial penetration of doxorubicin (red) from FITC-HA-CF/CB[8] hydrogel (green). Drug diffusion up to $900 \mu \mathrm{m}$ can be observed. A dead zone, of $400 \mu \mathrm{m}$, in which only doxorubicin fluorescence (red) is seen, extends into a diffusion zone in which the cellular stain DAPI (blue) can be observed.

that is less stiff (lower $\mathrm{G}^{\prime}$ ) than brain tissue, affording a hydrogel that can maintain tight apposition to tumour tissue while still being able to adapt to a healing resection cavity on account of the dynamic response to shear (Figure 5). It was found that $\mathrm{HA}-\mathrm{CF} / \mathrm{CB}[8]$ hydrogels have lower $\mathrm{G}^{\prime}$ and higher $G^{\prime \prime}$ values than tumour tissue. The greater loss modulus $\left(\mathrm{G}^{\prime \prime}\right)$ allows for the hydrogel to deform under viscous flow to dissipate the energy from the healing cavity, actively contributing to the maintenance of the cavityhydrogel contact. In addition to being softer than tissue from human brain $\left(\mathrm{G}^{*}\right.$ for the hydrogel can be formulated to be lower than the surrounding tissue) the ex vivo in- jection studies demonstrate that $\mathrm{HA}-\mathrm{CF} / \mathrm{CB}[8]$ hydrogels have excellent suitability towards trans-cranial injection. We have previously shown that physically cross-linked hydrogels lend themselves towards injectable materials on account of their reversible and transient nature. [31, 40, 25] The ability to rapidly self-heal, demonstrates the suitability towards clinical application. Furthermore, our ex vivo injection studies demonstrate that the HA-CF/CB[8] hydrogels are able to maintain their integrity after injection into tumour tissue.

By maintaining closer contact with the walls of the resection cavity, HA-CF / CB [8] hydrogels could provide slow, sustained release of therapeutics agents immediately following surgery, targetting a therapeutic opportunity with a variety of antineoplastic therapies. A window of time that is not typically used in current GB treatment protocols following surgery and prior to adjuvant CRT.

The therapeutic encapsulation and release properties need to be tailorable; it should be possible for the material's physical properties to be formulated on demand in the operating room. Owing to the enzyme-cleavable polysaccharide backbone, this hydrogel system allows for a sustained, slow release of synergistic drug compounds. Surgical staff would be able to formulate the delivery vehicle in the operating theatre with an encapsulated combination of therapies specific to the patient. Thus, HA$\mathrm{CF} / \mathrm{CB}[8]$ hydrogels not only improve on the overall distance achievable and the rate of drug diffusion, [19] but also increase the quality and surface area of contact with brain tissue than is currently possible with Gliadel ${ }^{\circledR}$ wafers. 22 .

We have described a hydrogel drug-delivery platform for $\mathrm{GB}$ and subsequently shown that the $\mathrm{HA}-\mathrm{CF} / \mathrm{CB}[8]$ hydrogels are less stiff than brain tissue, are mouldable, malleable, and injectable, are easily tailorable, and are biocompatible and biodegradable. These encouraging results will need to be validated through in vivo viability and efficacy studies.

We believe that $\mathrm{HA}-\mathrm{CF} / \mathrm{CB}[8]$ hydrogels provide an effective alternative to carmustine loaded wafers in order to bypass the BBB and provide synergistic, personalzsed therapies locally for patients with GB. Ultimately, we hope to progress to clinical trials with the aim of improving overall and progression-free survival for patients afflicted with this disease.

\section{Conclusions}

It has been shown through a wide variety of techniques, that HA-CF/CB[8] hydrogels may become strong candidates for drug-delivery vehicles, specifically for GB treatment. By examining the rheological properties of brain tissue, the biocompatible $\mathrm{HA}-\mathrm{CF} / \mathrm{CB}[8]$ hydrogel can be tuned to appropriately compliment the surrounding environment, ensuring continuous structural and shape remodeling that would be coherent with tissue healing. Delivery of small-molecule drug compounds and larger antibodies 
to primary GB cell lines has been achieved to a promising degree of efficacy but warrants further development in this area to maximize release quantities and to tune release rates. MTT viability assay results have been further reinforced by microscopic imaging of the cell lines showing cellular stress and inflammation after drug/hydrogel treatment. Ex vivo injection of cargo loaded HA-CF/CB[8] hydrogel into resected human tissue samples demonstrates efficient apposition of the gel and diffusive release of the compounds into the surrounding tissue. Future in vivo experiments will prove to be the real test of the hydrogel efficacy and the feasibility of such surgical procedures.

\section{Data Availability}

Datasets related to this article can be found at 10.17863/CAM.22567, hosted at the Cambridge Data Repository.

\section{Acknowledgements}

This work was supported by The Brain Tumour Charity (RG89672), the National Institute for Health Research Cambridge Biomedical Research Centre; the Higher Education Funding Council for England. We acknowledge the Human Research Tissue Bank and Biomedical Research Centre for the tissue being accessed through the Human Research Tissue Bank. The Human Research Tissue Bank is supported by the NIHR Cambridge Biomedical Research Centre. MJR thanks the University of Cambridge Chemical Biology and Molecular Medicine Ph.D. Training Programme for funding. CCP is thankful for the support of the EPSRC and the Brain Tumour Charity for funding. JHM acknowledges the support of the Gates Cambridge Scholarship programme. AKK was supported by a studentship from the Johm and Lucille van Geest Foundation. We would like to thank Dominique Hoogland, and Anthony Tabet for scientific discussions.

\section{References}

[1] C. Neider, A. Grosu, S. Astner, M. Molls, Treatment of Unresectable Glioblastoma Multiforme, Antican. Res. 25 (2005) 4605-4610.

[2] R. Stupp, W. P. Mason, M. J. van den Bent, M. Weller, B. Fisher, M. J. Taphoorn, K. Belanger, A. A. Brandes, C. Marosi, U. Bogdahn, J. Curschmann, R. C. Janzer, S. K. Ludwin, T. Gorlia, A. Allgeier, D. Lacombe, J. G. Cairncross, E. Eisenhauer, R. O. Mirimanoff, Radiotherapy plus Concomitant and Adjuvant Temozolomide for Glioblastoma, N. Engl. J. Med. 352 (10) (2005) 987-996. doi:10.1056/NEJMoa043330

[3] J. Perry, A. Chambers, K. Spithoff, N. Laperriere, Gliadel wafers in the treatment of malignant glioma: a systematic review., Curr. Oncol Rep. 14 (5) (2007) 189-94.

[4] D. Krex, B. Klink, C. Hartmann, A. von Deimling, T. Pietsch, M. Simon, M. Sabel, J. P. Steinbach, O. Heese, G. Reifenberger, M. Weller, G. Schackert, Long-term survival with glioblastoma multiforme, Brain 130 (10) (2007) 2596-2606. doi:10.1093/ brain/awm204.
[5] E. L. Chang, S. Akyurek, T. Avalos, N. Rebueno, C. Spicer, J. Garcia, R. Famiglietti, P. K. Allen, K. S. C. Chao, A. Mahajan, S. Y. Woo, M. H. Maor, Evaluation of Peritumoral Edema in the Delineation of Radiotherapy Clinical Target Volumes for Glioblastoma, Int. J. Radiat. Oncol. Biol. 68 (1) (2007) 133-150. doi:10.1016/j.ijrobp.2006.12.009

[6] M. Jackson, F. Hassiotou, A. Nowak, Glioblastoma stem-like cells: at the root of tumor recurrence and a therapeutic target, Carcinogenesis 36 (2) (2015) 177-185. doi:10.1093/carcin/ bgu243

[7] L. E. Gaspar, B. J. Fisher, D. R. Macdonald, D. V. Leber, E. C. Halperin, S. Schold, J. Cairncross, Supratentorial malignant glioma: Patterns of recurrence and implications for external beam local treatment, Int. J. Radiat. Oncol. Biol. Phys. 24 (1) (1992) 55-57. doi:10.1016/0360-3016(92)91021-E

[8] G. Dresemann, Temozolomide in malignant glioma, OncoTargets Ther. 3 (2010) 139. doi:10.2147/OTT.S5480

[9] B. J. Denny, R. T. Wheelhouse, M. F. G. Stevens, L. L. H. Tsang, J. A. Slack, NMR and Molecular Modeling Investigation of the Mechanism of Activation of the Antitumor Drug Temozolomide and Its Interaction with DNA, Biochemistry 33 (31) (1994) 9045-9051. doi:10.1021/bi00197a003

[10] L. Meer, R. C. Janzer, P. Kleihues, G. F. Kolar, In vivo metabolism and reaction with dna of the cytostatic agent, 5-(3,3-dimethyl-1-triazeno)imidazole-4-carboxamide (DTIC), Biochemic. Pharmacol. 35 (19) (1986) 3243-3247. doi:10.1016/0006-2952(86)90419-3

[11] C. Watts, An Evaluation of the Tolerability and Feasibility of Combining 5-Amino-Levulinic Acid (5-ALA) With Carmustine Wafers (Gliadel) in the Surgical Management of Primary Glioblastoma (GALA-5 Trial), Tech. rep., University College London, London (2011).

[12] W. Sage, M. Guilfoyle, C. Luney, A. Young, R. Sinha, D. Sgubin, J. H. Mcabee, R. Ma, S. Jefferies, R. Jena, F. Harris, K. Allinson, T. Matys, W. Qian, T. Santarius, S. Price, C. Watts, Local alkylating chemotherapy applied immediately after 5-ALA guided resection of glioblastoma does not provide additional benefit, J. Neuro. Oncol. 136 (2) (2018) 273-280.

[13] H.-A. Leroy, M. Vermandel, J.-P. Lejeune, S. Mordon, N. Reyns, Fluorescence guided resection and glioblastoma in 2015: A review, Lasers Surg. Med. 47 (5) (2015) 441-451. doi:10.1002/ 1sm.22359

[14] P. V. Iriarte, J. Hananian, J. A. Cortner, Central nervous system leukemia and solid tumors of childhood:Treatment with 1,3-bis (2-chloroethyl)-1-nitrosourea (BCNU), Cancer 19 (9) (1966) 1187-1194. doi:10.1002/1097-0142(196609)19: 9<1187: :AID-CNCR2820190902>3.0.C0;2-T

[15] P. Moshayedi, G. Ng, J. C. Kwok, G. S. Yeo, C. E. Bryant, J. W. Fawcett, K. Franze, J. Guck, The relationship between glial cell mechanosensitivity and foreign body reactions in the central nervous system, Biomaterials 35 (13) (2014) 3919-3925. doi:10.1016/j.biomaterials.2014.01.038

[16] J. M. Anderson, Biological Response to Materials, Annu. Rev. Mater. Res 31 (2001) 81-110.

[17] M. McGirt, K. Chaichana, M. Gathinji, F. Attenello, K. Than, A. Olivi, J. Weingart, H. Brem, A. Quinones-Hinojosa, Gliadel (BCNU) wafer plus concomitant temozolomide therapy after primary resection of glioblastoma multiforme, J. Neurosurg. 110 (3) (2009) 583-588. doi:10.3171/2008.5.17557

[18] F. J. Attenello, D. Mukherjee, G. Datoo, M. J. McGirt, E. Bohan, J. D. Weingart, A. Olivi, A. Quinones-Hinojosa, H. Brem, Use of Gliadel (BCNU) Wafer in the Surgical Treatment of Malignant Glioma: A 10-Year Institutional Experience, Ann. Surg. Oncol. 15 (10) (2008) 2887-2893.

[19] A. B. Fleming, W. M. Saltzman, Pharmacokinetics of the Carmustine Implant, Clin. Pharmacokinet. 41 (6) (2002) 403-419. doi:10.2165/00003088-200241060-00002

[20] L. K. Fung, M. Shin, B. Tyler, H. Brem, W. M. Saltzman, Chemotherapeutic Drugs Released from Polymers: Distribution of 1,3-bis(2-chloroethyl)-l-nitrosourea in the Rat Brain, Pharm. Res. 13 (5) (1996) 671-682. doi:10.1023/A:1016083113123 
[21] M. Westphal, D. C. Hilt, E. Bortey, P. Delavault, R. Olivares, P. C. Warnke, I. R. Whittle, J. Jääskeläinen, Z. Ram, A phase 3 trial of local chemotherapy with biodegradable carmustine (BCNU) wafers (Gliadel wafers) in patients with primary malignant glioma., Neuro. Oncol. 5 (2) (2003) 79-88. doi:10.1215/S1522-8517-02-00023-6

[22] A. Bregy, A. H. Shah, M. V. Diaz, H. E. Pierce, P. L. Ames, D. Diaz, R. J. Komotar, The role of Gliadel wafers in the treatment of high-grade gliomas, Expert Rev. Anticancer. Ther. 13 (12) (2013) 1453-1461.

[23] M. Westphal, Z. Ram, V. Riddle, D. Hilt, E. Bortey, Gliadel® wafer in initial surgery for malignant glioma: long-term followup of a multicenter controlled trial, Acta Neurochir. 148 (3) (2006) 269-275. doi:10.1007/s00701-005-0707-z

[24] C. J. Kearney, D. J. Mooney, Macroscale delivery systems for molecular and cellular payloads Nature Publishing Group 12 (11) (2013) 1004-1017. doi:10.1038/nmat3758 URL http://dx.doi.org/10.1038/nmat3758

[25] M. J. Rowland, M. Atgie, D. Hoogland, O. A. Scherman, Preparation and Supramolecular Recognition of Multivalent Peptide-Polysaccharide Conjugates by Cucurbit[8] uril in Hydrogel Formation., Biomacromolecules 16 (8) (2015) 2436-43. doi:10.1021/acs.biomac.5b00680

[26] K. Pogoda, L. Chin, P. C. Georges, F. J. Byfield, R. Bucki, R. Kim, M. Weaver, R. G. Wells, C. Marcinkiewicz, P. A. Janmey, Compression stiffening of brain and its effect on mechanosensing by glioma cells., New J. Phys. 16 (2014) 075002. doi:10.1088/1367-2630/16/7/075002

[27] E. M. Kenney-Herbert, S. L. Ball, T. M. F. Al-Mayhani, C. Watts, Glioblastoma cell lines derived under serum-free conditions can be used as an in vitro model system to evaluate therapeutic response, Cancer Lett. 305 (1) (2011) 50-57. doi:10.1016/j.canlet.2011.02.025

[28] T. M. Fael Al-Mayhani, S. L. Ball, J.-W. Zhao, J. Fawcett, K. Ichimura, P. V. Collins, C. Watts, An efficient method for derivation and propagation of glioblastoma cell lines that conserves the molecular profile of their original tumours, J. Neurosci. Methods 176 (2) (2009) 192-199. doi:10.1016/j. jneumeth.2008.07.022

[29] T. Arai, T. Joki, M. Akiyama, M. Agawa, Y. Mori, H. Yoshioka, T. Abe, Novel drug delivery system using thermoreversible gelation polymer for malignant glioma, J. Neuro. Oncol. 77 (1) (2006) 9-15.

[30] A. Shervington, V. Pawar, S. Menon, D. Thakkar, R. Patel, The sensitization of glioma cells to cisplatin and tamoxifen by the use of catechin, Mol. Bio. Rep. 36 (5) (2009) 1181-1186. doi:10.1007/s11033-008-9295-3.

[31] E. A. Appel, R. A. Forster, M. J. Rowland, O. A. Scherman, The control of cargo release from physically crosslinked hydrogels by crosslink dynamics, Biomaterials 35 (37) (2014) 9897-9903.

[32] J. H. M. de Lange, N. W. Schipper, G. J. Schuurhuis, T. K. ten Kate, T. H. M. Van Heijningen, H. M. Pinedo, J. Lankelma, J. P. A. Baak, Quantification by laser scan microscopy of intracellular doxorubicin distribution, Cytometry 13 (6) (1992) 571-576. doi:10.1002/cyto.990130604

[33] C. Cadart, E. Zlotek-Zlotkiewicz, M. Le Berre, M. Piel, H. K. Matthews, Exploring the Function of Cell Shape and Size during Mitosis, Dev. Cell. 29 (2) (2014) 159-169. doi:10.1016/j. devcel.2014.04.009.

[34] R. Asher, A. Bignami, Hyaluronate binding and CD44 expression in human glioblastoma cells and astrocytes, Exp. Cell. Res. 203 (1) (1992) 80-90.

[35] J. C. Kiefer, Back to basics: Sox genes, Dev. Dynam. 236 (8) (2007) 2356-2366. doi:10.1002/DVDY.21218.

[36] U. Lendahl, L. B. Zimmerman, R. D. McKay, CNS stem cells express a new class of intermediate filament protein, Cell 60 (4) (1990) 585-595. doi:10.1016/0092-8674(90)90662-X

[37] C. A. Dinarello, Interleukin-1., Rev. Infect. Dis. 6 (1) (1997) 51-95.

[38] R. J. Simpson, A. Hammacher, D. K. Smith, J. M. Matthews, L. D. Ward, Interleukin-6: structure-function relationships.,
Protein Sci. 6 (5) (1997) 929-55. doi:10.1002/pro.5560060501

[39] U. Gaur, B. B. Aggarwal, Regulation of proliferation, survival and apoptosis by members of the TNF superfamily, Biochem. Pharmacol. 66 (8) (2003) 1403-1408. doi:10.1016/ S0006-2952(03) 00490-8

[40] E. A. Appel, J. del Barrio, X. J. Loh, O. A. Scherman, Supramolecular polymeric hydrogels, Chem. Soc. Rev. 41 (18) (2012) 6195

[41] E. A. Appel, X. J. Loh, S. T. Jones, C. A. Dreiss, O. A. Scherman, Sustained release of proteins from high water content supramolecular polymer hydrogels Biomaterials 33 (18) (2012) 4646-4652. doi:10.1016/j.biomaterials.2012.02.030 URL http://dx.doi.org/10.1016/j.biomaterials.2012.02. 030

[42] G. Xing, M. Ren, A. Verma, Divergent Temporal Expression of Hyaluronan Metabolizing Enzymes and Receptors with Craniotomy vs. Controlled-Cortical Impact Injury in Rat Brain: A Pilot Study, Front. Neurosci. 5 (2014) 173. doi:10.3389/fneur. 2014.00173

[43] T. C. Laurent, J. R. Fraser, Hyaluronan., FASEB J 6 (7) (1992) 2397-404. 